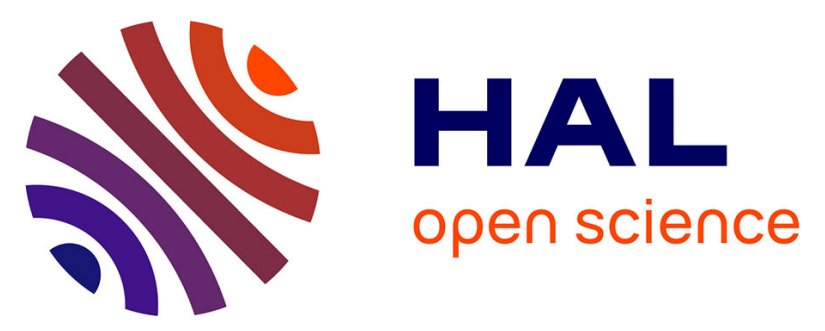

\title{
Prevalence and significance of rare RYR2 variants in arrhythmogenic right ventricular cardiomyopathy/dysplasia: results of a systematic screening.
}

Nathalie Roux-Buisson, Estelle Gandjbakhch, Erwan Donal, Vincent Probst, Jean-Claude Deharo, Philippe Chevalier, Didier Klug, Nicolas Mansencal, Etienne Delecretaz, Pierre Cosnay, et al.

\section{- To cite this version:}

Nathalie Roux-Buisson, Estelle Gandjbakhch, Erwan Donal, Vincent Probst, Jean-Claude Deharo, et al.. Prevalence and significance of rare RYR2 variants in arrhythmogenic right ventricular cardiomyopathy/dysplasia: results of a systematic screening.. Heart Rhythm, 2014, pp.1999-2009. inserm01120324

\section{HAL Id: inserm-01120324 https://www.hal.inserm.fr/inserm-01120324}

Submitted on 25 Feb 2015

HAL is a multi-disciplinary open access archive for the deposit and dissemination of scientific research documents, whether they are published or not. The documents may come from teaching and research institutions in France or abroad, or from public or private research centers.
L'archive ouverte pluridisciplinaire HAL, est destinée au dépôt et à la diffusion de documents scientifiques de niveau recherche, publiés ou non, émanant des établissements d'enseignement et de recherche français ou étrangers, des laboratoires publics ou privés. 
Elsevier Editorial System(tm) for Heart Rhythm

Manuscript Draft

Manuscript Number: HR-0131444R2

Title: PREVALENCE AND SIGNIFICANCE OF RARE RYR2 VARIANTS IN ARRHYTHMOGENIC RIGHT VENTRICULAR CARDIOMYOPATHY/DYSPLASIA: RESULTS OF A SYSTEMATIC SCREENING

Article Type: Original-clinical-Genetic

Keywords: Arrhythmogenic right ventricular dysplasia/cardiomyopathy; RYR2 gene; mutation; genetic testing

Corresponding Author: Dr. Nathalie Roux-Buisson,

Corresponding Author's Institution: Hospital

First Author: Nathalie Roux-Buisson

Order of Authors: Nathalie Roux-Buisson; Estelle Gandjbakhch; Erwan Donal; Vincent Probst; Deharo Jean-Claude; Philippe Chevalier; Didier Klug; Nicolas Mansencal; Etienne Delecretaz; Pierre Cosnay; Patrice Scanu; Dagmar Keller; Jonathan Trapani; Pierre Fouret; Véronique Fressart; Julien Fauré; Joel Lunardi; Philippe Charron

Manuscript Region of Origin: FRANCE

Abstract: ABSTRACT

Background

Arrhythmogenic right ventricular Cardiomyopathy/Dysplasia (ARVC/D) is a genetic disease predominantly caused by desmosomal gene mutations that account for only $\sim 50 \%$ of cases. RYR 2 gene mutations usually cause Catecholaminergic Polymorphic Ventricular Tachycardia (CPVT) but have been associated with peculiar phenotype named ARVC2.

Objectives

We aim to determine the prevalence and phenotype associated with RYR2 mutations in a large ARVC/D population.

Methods

We analyzed the whole RYR2 coding sequence by Sanger sequencing in 64 ARVC/D probands without desmosomal gene mutations.

Results

We have identified six rare missense variants p.P1583S, p.A2213S, p.G2367R, p.Y2932H, p.V3219M and p.L4670V. It corresponds to a prevalence of 9\% of rare RYR2 variants in ARVC/D population (6 probands /64) that is significantly higher than the estimated rate of rare RYR2 variants in control (Fisher test, $\mathrm{p}=0.03$ ). Phenotypes associated with RYR2 variants were similar to desmosome-related ARVC/D, associating typical ECG abnormalities at rest, frequent monomorphic ventricular tachycardia, right ventricular dilatation, wall motion abnormalities and fibro-fatty replacement when histopathological examination was available.

Conclusion

In this first systematic screening of the whole coding region of the RYR2 gene in a large ARVC/D cohort without mutation in desmosomal genes, we show that putative RYR 2 mutations are frequent $(9 \%$ of 
ARVC/D probands) and are associated with a conventional phenotype of ARVC/D, in contrast with previous findings. The results support the role of RYR2 gene in conventional ARVC/D. 


\section{CONFLICT OF INTEREST STATEMENT - HeartRhythm (First and Corresponding Author(s) Must Sign)}

Thank you for your submission to the HeartRhythm journal. CONFLICTS OF INTEREST FOR ALL AUTHORS MUST BE STATED ON THE TITLE PAGE. Please have the first and corresponding author(s) sign and upload with your manuscript submission. Its purpose is to inform all interested parties of any significant affiliations or relationships you may have with any commercial enterprise or any other potential conflicts of interest. This is a standard form required by most leading journals.

1. Were you loaned any equipment, materials or medication for this study?

Yes No $\mathrm{X}$ Explain

2. Were you given any equipment, materials or medication for this study?

Yes__ No $\mathrm{X}$ Explain

3. Did you receive any funding to support your research for this article?

Yes $\mathrm{X}$ No Explain This work was supported by institutional grants from Assistance Publique - Hôpitaux de Paris [PHRC programme hospitalier de recherche clinique AOM05073].

4. Were you provided with any honoraria, payment or other compensation for your work on this study? Yes__ No $\mathrm{X}$ Explain

5. Did you receive any stock options, stock ownership or other valuable materials in conjunction with this study from any source whatsoever?

Yes__ No $\mathrm{X}$ Explain

6. Did you receive any outside financial support for travel or lectures to present the information covered in this study?

Yes _ No $\quad$ X Explain

7. Do you have any financial relationship with any entity that may closely compete with the medications, materials or instruments covered by your study?

Yes _ No N $\mathrm{X}$ Explain

8. Do you own or have you applied for any patents in conjunction with the instruments, medications or materials discussed in this study?

Yes _ No $\quad \mathrm{X}$ Explain

9. Do you receive any compensation for any therapy discussed in your article?

Yes__ No $\quad \mathrm{X}$ Explain

10. Does anyone in your immediate family have a conflict of interest that would be covered by any of the above questions? (This would include closely held family trusts, limited liability corporations, etc.)

Yes _ No N $\mathrm{X}$ Explain

If you have any doubts about the nature of your conflict, please contact Douglas P. Zipes M.D., Editor-in-Chief.

\begin{tabular}{lllll} 
Manuscript Number or & SIGNIFICANCE OF & RYR2 & MUTATIONS IN \\
Title: & ARRHYTHMOGENIC & RIGHT & VENTRICULAR \\
& CARDIOMYOPAHY/DYSPLASIA: & A & SYSTEMATIC \\
& SCREENING & & \\
\hline
\end{tabular}

Signed:/Date

$2013 / 11 / 15$ 


\section{CONFLICT OF INTEREST STATEMENT - HeartRhythm}

(First and Corresponding Author(s) Must Sign)

Print Name:

Roux-Buisson 
Dr Philippe Charron

$\mathrm{MD}, \mathrm{PhD}$, FESC, Ass. Prof.

Département de Cardiologie,

Hôpital Pitié-Salpêtrière,

47 Boulevard de l'Hôpital,

75013 Paris, France.

Email: philippe.charron@psl.aphp.fr

For the Editor-In-Chief,

Heart Rhythm journal

July 09th, 2014

Dear Editor,

Please find enclosed our revised manuscript entitled "PREVALENCE AND SIGNIFICANCE OF RARE RYR2 VARIANTS IN ARRHYTHMOGENIC RIGHT VENTRICULAR CARDIOMYOPATHY/DYSPLASIA: RESULTS OF A SYSTEMATIC SCREENING " by RouxBuisson et al., which we submit for publication in Heart Rhythm as an original article.

I would like to thank the reviewers for their constructive comments.

I added a "clinical perspectives" paragraph as requested.

You will find below a detailed answer to the reviewer's comments and also the revised manuscript.

I hope the reviewers and yourself will find this new manuscript to your satisfaction.

Thank you in advance for the consideration given to our work.

Yours sincerely,

Philippe Charron, MD, PhD, Assoc. Prof. 


\section{Reviewer \#1:}

We thank the reviewer for his/her comments.

$>$ The stated $P$ value of 0.003 by Fisher is important and should also appear in the abstract.

Answer: We modified the manuscript as recommended by the reviewer:

Abstract, page 4, lines 17-18

"It corresponds to a prevalence of $9 \%$ of rare RYR2 variants in ARVC/D population (6 probands/64) that is significantly higher than the estimated rate of rare RYR2 variants in control (Fisher test, $p=0.03$ )."

$>$ In the abstract, the comment: ":not overlapping with CPVT" is an overstatement and should be removed.

Answer: We modified the manuscript as recommended by the reviewer:

Abstract, page 5, line 5

"In this first systematic screening of the whole coding region of the RYR2 gene in a large ARVC/D cohort without mutation in desmosomal genes, we show that putative RYR 2 mutations are frequent (9\% of ARVC/D probands) and are associated with a conventional phenotype of ARVC/D, in contrast with previous findings."

The limitations section should include the fact that the authors limited their analysis to the 1994 Task Force criteria, and indicate why.

Answer: The reviewer is right. We modified the manuscript as suggested:

Abstract, page 18, lines 13-14

"At last, the ARVC/D probands were selected according to the 1994 Task Force Criteria as this cohort was prospectively recruited before the publication of the revised TFC." 


\section{Reviewer \#2:}

We thank the reviewer for his/her comments.

The questions raised were adequately addressed.

> Probably slightly modify the title: Prevalence ...: results of a systematic screening

We modified the title as follow: "PREVALENCE AND SIGNIFICANCE OF RARE RYR2 VARIANTS IN ARRHYTHMOGENIC RIGHT VENTRICULAR CARDIOMYOPATHY/DYSPLASIA: RESULTS OF A SYSTEMATIC SCREENING”" 
2 Title: PREVALENCE AND SIGNIFICANCE OF RARE RYR2 VARIANTS IN

3 ARRHYTHMOGENIC

RIGHT

VENTRICULAR

\section{CARDIOMYOPATHY/DYSPLASIA: RESULTS OF A SYSTEMATIC SCREENING}

5 Short title: RYR2 mutations in Arrhythmogenic Right Ventricular

6 Cardiomyopathy/Dysplasia

7

8

9

Authors: Nathalie Roux-Buisson, $\mathrm{MD}, \mathrm{PhD}^{1,2,3 \S}$, Estelle Gandjbakhch, $\mathrm{MD}, \mathrm{PhD}^{4,5 \S}$, Erwan Donal, $\mathrm{MD}, \mathrm{PhD}^{6}$, Vincent Probst, $\mathrm{MD}, \mathrm{PhD}^{7}$, Jean-Claude Deharo, $\mathrm{MD}^{8}$, Philippe Chevalier, $\mathrm{MD}, \mathrm{PhD}^{9}$, Didier Klug, $\mathrm{MD}^{10}$, Nicolas Mansencal, $\mathrm{MD}, \mathrm{PhD}^{11}$, Etienne Delacretaz, MD, $\mathrm{PhD}^{12}$, Pierre Cosnay, $\mathrm{MD}^{13}$, Patrice Scanu, $\mathrm{MD}^{14}$, Fabrice Extramiana, $\mathrm{MD}, \mathrm{PhD}^{15}$, Dagmar Keller, $\mathrm{MD}^{16}$, Françoise Hidden-Lucet, $\mathrm{MD}^{4,5}$, Jonathan Trapani ${ }^{2}$, Pierre Fouret, $\mathrm{MD}, \mathrm{PhD}^{4,17}$, Robert Frank, $\mathrm{MD}^{5}$, Veronique Fressart, $\mathrm{MD}, \mathrm{PhD}^{5,18}$, Julien Fauré, $\mathrm{PhD}^{1,2,3}$, Joel Lunardi, PharmD, $\mathrm{PhD}^{1,2,3}$ and Philippe Charron, $\mathrm{MD}, \mathrm{PhD}^{4,5,11^{*}}$

The number of authors is justified by the fact that this manuscript results from a multicenter study, and there is one author from each center.

\section{Affiliations:}

${ }^{1}$ INSERM U836, Grenoble Institut des Neurosciences, Equipe Muscle et Pathologies, Grenoble, France,

${ }^{2}$ CHRU de Grenoble, Hopital Michallon, Biochimie et Génétique Moléculaire, Grenoble, France,

${ }^{3}$ Université Joseph Fourier, Grenoble, France, 
1

$2 \quad{ }^{5} \mathrm{AP}-\mathrm{HP}$; centre de référence maladies cardiaques héréditaires; ICAN, Hôpital Pitié-

3 Salpêtrière

$4 \quad{ }^{6}$ Service de Cardiologie, Hôpital Pontchaillou, Rennes, France

$5{ }^{7}$ Institut du thorax, service de cardiologie du CHU de Nantes and INSERM UMR 915,

$6 \quad$ Université de Nantes, Nantes, France

$7 \quad{ }^{8}$ Service de Cardiologie, Hôpital La Timone, Marseille, France

$8{ }^{9}$ Service de Cardiologie, Hôpital Est, Lyon, France

$9{ }^{10}$ Service de Cardiologie, Hôpital Cardiologique, Lille, France

${ }^{11}$ Université de Versailles-Saint Quentin, Hôpital Ambroise Paré, AP-HP, Boulogne, France

${ }^{12}$ Service de Cardiologie, Hôpital de l'Ile, Berne, Suisse

${ }^{13}$ Service de Cardiologie B, CHU Tours, Tours, France

${ }^{14}$ Service de Cardiologie, Hôpital Côte de Nacre, Caen, France

${ }^{15}$ Service de Cardiologie, Hôpital Lariboisière, AP-HP, Université Paris 7, Paris, France

${ }^{16}$ Service de Cardiologie, Hôpital Universitaire de Bâle, Bâle, Suisse

${ }^{17}$ APHP, Hôpital Pitié-Salpêtrière, Service d'Anatomie pathologique, Paris, France

${ }^{18}$ AP-HP, Hôpital Pitié-Salpêtrière, Service de Biochimie, Unité de Cardiogénétique et Myogénétique, Paris, France

§These authors contributed equally to this work

Fundings:

This work was supported by grants from Assistance Publique-Hôpitaux de Paris [PHRC programme hospitalier de recherche clinique AOM05073]. 


\section{Conflict of interest: none}

2

3 *Corresponding author: Philippe Charron Tel: +33 1421613 47; fax: +331 421613 64,

$4 \quad$ Email: philippe.charron@psl.aphp.fr

5 Address: AP-HP, Hôpital Pitié-Salpêtrière, Centre de référence pour les maladies cardiaques

6 héréditaires, Paris, France

7

$8 \quad$ Word count: $\mathbf{5 0 3 3}$

9 


\section{ABSTRACT \\ 2 Background}

Arrhythmogenic right ventricular Cardiomyopathy/Dysplasia (ARVC/D) is a genetic

4 disease predominantly caused by desmosomal gene mutations that account for only $\sim 50 \%$ of

5 cases. RYR2 gene mutations usually cause Catecholaminergic Polymorphic Ventricular

6 Tachycardia (CPVT) but have been associated with peculiar phenotype named ARVC2.

\section{$7 \quad$ Objectives}

8 We aim to determine the prevalence and phenotype associated with $R Y R 2$ mutations in a large

$9 \quad$ ARVC/D population.

10

11

\section{Methods}

We analyzed the whole $R Y R 2$ coding sequence by Sanger sequencing in 64 ARVC/D probands without desmosomal gene mutations.

\section{Results}

We have identified six rare missense variants p.P1583S, p.A2213S, p.G2367R, p.Y2932H, p.V3219M and p.L4670V. It corresponds to a prevalence of $9 \%$ of rare $R Y R 2$ variants in ARVC/D population (6 probands/64) that is significantly higher than the estimated rate of rare $R Y R 2$ variants in control (Fisher test, $\mathrm{p}=0.03$ ). Phenotypes associated with $R Y R 2$ variants were similar to desmosome-related ARVC/D, associating typical ECG abnormalities at rest, frequent monomorphic ventricular tachycardia, right ventricular dilatation, wall motion abnormalities and fibro-fatty replacement when histopathological examination was available. 
2 In this first systematic screening of the whole coding region of the $R Y R 2$ gene in a large

3 ARVC/D cohort without mutation in desmosomal genes, we show that putative $R Y R 2$ 4 mutations are frequent (9\% of ARVC/D probands) and are associated with a conventional 5 phenotype of $A R V C / D$, in contrast with previous findings. The results support the role of $6 \quad R Y R 2$ gene in conventional ARVC/D.

7

8

9 Keywords: Arrhythmogenic right ventricular dysplasia/cardiomyopathy; $R Y R 2$ gene; mutation

Abbreviations:

AA: amino acid

ARVC/D: Arrhythmogenic Right Ventricular Cardiomyopathy/Dysplasia

CPP : ethical committee (comité de protection des personnes)

CPVT: Catecholaminergic Polymorphic Ventricular Tachycardia

DNA: Deoxyribonucleic acid

ECG: electrocardiogram

EP: electrophysiologic study

EVS: Exome Variant Server database

LBBB: left bundle branch block

LV: left ventricle

MRI: Magnetic Resonance Imaging

NSVT: non-sustained ventricular tachycardia

RBBB: right bundle branch block 
1 RV: right ventricle

2 RVOT: right ventricle outflow tract

3 RYR2: Ryanodine receptor type 2

4 SNP: single nucleotide polymorphism

5 SVT: sustained ventricular tachycardia

6 TFC: Task Force Criteria

7 TWI: T-wave inversion

8 Vec: ventricular ectopies

$9 \quad$ VT: ventricular tachycardia

10 WMA: wall motion abnormalities 


\section{INTRODUCTION}

2 Arrhythmogenic Right Ventricular Cardiomyopathy/Dysplasia (ARVC/D) is a rare cardiac muscle disorder characterised by progressive fibro-fatty replacement of the myocardium. The right ventricle is predominantly affected but left ventricular involvement is also present in more than half of the cases ${ }^{1}$. These structural alterations can lead to ventricular arrhythmias and heart failure. ARVC/D is a frequent cause of sudden death in young people and athletes. The diagnosis of ARVC/D is currently based on the presence of major and minor standardised Task Force criteria (TFC) that consider ventricular arrhythmias episodes, electrocardiographic abnormalities, right ventricular function and morphology, histopathology, family history and genetic status ${ }^{2}$.

ARVC/D is usually inherited as an autosomal dominant disease with reduced penetrance and variable expression. So far, the major genes involved in ARVC/D encode components of the cardiac desmosome: plakophilin-2 $(P K P 2)^{3}$, desmoglein-2 $(D S G 2)^{4,5}$, plakoglobin $(J U P)^{6}$, desmoplakin $(D S P)^{7}$ and desmocollin-2 $(D S C 2)^{8,9}$. Comprehensive mutation screening of the five main desmosomal ARVC/D genes can detect genetic abnormalities in at least $40-50 \%$ of probands ${ }^{10}$. Non-desmosomal genes have been also associated with ARVC/D phenotypes including the cardiac ryanodine receptor type 2 gene $(R Y R 2)^{11}$, the transforming growth factor beta 3 gene $(T G F B 3)^{12}$, the TMEM43 gene ${ }^{13}$ and more recently the lamin $\mathrm{A} / \mathrm{C}(L M N A)^{14}$, the titin $(T T N)^{15}$, the desmin $(D E S)^{16}$ and the phospholamban $(P L N)^{17}$ genes. Mutations in the $R Y R 2$ gene are usually associated with catecholaminergic polymorphic ventricular tachycardia (CPVT), a rare and severe inherited arrhythmia without structural cardiac abnormality ${ }^{18,19}$ (http://www.fsm.it/cardmoc/).

$R Y R 2$ is one of the largest human genes (105 exons) encoding a mRNA of 16365 bp (NM_021991.2). Nava et al reported in 1988 a family with autosomal dominant form of right ventricular cardiomyopathy (supported by histological data) associated with polymorphic 
1 ventricular tachycardia induced by exercise stress testing and juvenile sudden death ${ }^{20}$.

2 Rampazzo et al mapped then the locus to chromosome 1q42-q43 and identified RYR2

3 mutations in four independent families with the same clinical presentation of ARVC/D

4 (named ARVC/D2) ${ }^{11,21}$. This clinical presentation differs from desmosome-related forms of

$5 \mathrm{ARVC} / \mathrm{D}$ and is rather close to CPVT because of the presence of effort-induced ventricular

6 arrhythmias, its high penetrance and a 1:1 sex ratio. The association between typical form of

$7 \quad \mathrm{ARVC} / \mathrm{D}$ and $R Y R 2$ mutations remains unclear and the prevalence of $R Y R 2$ mutations in the

8 ARVC/D population remains unknown since very few mutations have been associated to

$9 \quad \mathrm{ARVC} / \mathrm{D}^{11,22-24}$.

In this study, we aimed to determine the prevalence of $R Y R 2$ mutations in a large cohort of 64 well clinically characterised ARVC/D probands for whom mutations in PKP2, DSG2, DSP, $D S C 2$ and JUP were previously excluded. Sequencing of the entire coding region of $R Y R 2$ in these ARVC/D probands led to the identification of 6 putative missense mutations in 6 unrelated probands. The pathogenic role of the variations is discussed as well as the consequences for clinical practice.

\section{METHODS}

\section{Patients}

This multicenter prospective study included a cohort of unrelated probands recruited in France and Switzerland with a diagnosis of ARVC/D according to the TFC used at time of enrolment $^{25}$ and then focussed on 64 probands for whom no mutation were identified in $P K P 2, D S G 2, D S P, J U P$ and DSC2 genes ${ }^{10}$.

Clinical evaluation of all probands was performed as described previously ${ }^{10}$ and included: evaluation of personal and familial history, physical examination, 12-lead standard ECG, standard echocardiography, cardiac Magnetic Resonance Imaging (MRI) or right ventricular (RV) angiography, 24-hours ambulatory electrocardiogram (ECG) and signal-averaged- 
$1 \mathrm{ECG}^{10}$. Baseline exercise test was performed in all probands, except in very particular

2 situations requiring urgent therapeutic management (such as implantable cardiac defibrillator

3 or anti-arrhythmic drugs). Electrophysiologic (EP) study was performed when considered

4 clinically relevant by the physician, according to the following protocol: 2 different sites, 2

5 rates, with up to 3 extra stimuli, at baseline and with infusion of isoproterenol. In the case of

6 cardiac transplant, pathological analysis of the explanted heart was performed. Clinical

7 evaluation of relatives was performed when available. This study was approved by the Pitié-

8 Salpêtrière Hospital ethical committee (CPP) and written informed consent was obtained from

9 all individuals.

\section{Genetic analysis}

For each proband, the 105 exons and intron-exon junctions of the $R Y R 2$ gene were amplified from genomic DNA (OMIM 180902, transcript: NM_021991.2, protein: 4967 AA, Q92736-1, primer sequences available upon request). The analysis of the entire coding sequence of $R Y R 2$ was performed by direct sequencing on an ABI 3130 DNA sequencer (PE Applied Biosystems ${ }^{\circledR}$, Foster City, USA).

When unreported variant were detected, they were searched among 400 chromosomes from ethnically matched and healthy control subjects (Caucasian $n=400$ or Maghrebian $n=134$ ) by direct sequencing or by denaturating high-performance liquid chromatography (Wave Transgenomic Inc®, Cambridge,USA).

Upon identification, the likelihood of a pathogenic effect of an unreported $R Y R 2$ variant was based on (i) the absence of the variant in the control population and an allele frequency inferior to $1 / 10000$ in the databases NCBI SNPs, 1000 Genome and Exome Variant Server (http://www.ncbi.nlm.nih.gov/snp, http///browser.1000genomes.org/index.html, http://evs.gs.washington.edu/EVS), (ii) the conservation of the mutated residue among species and $R Y R$ isoforms and (iii) the predicted effect of the mutation by three appropriate software 
2 http://sift.bii.astar.edu.sg/, http://snps-and-go.biocomp.unibio.it/snps-and-go/ ). The segregation analysis within the family was performed when the relatives DNAs and clinical

4 data were available.

\section{Statistical Analysis}

6 The frequency of the "genetic background noise" of rare $R Y R 2$ missense variants in the general population was estimated using data from the Exome Variant Server database (EVS). By using the coverage data available in EVS website, we find that 25938 positions covering the RYR2 exons and introns boundaries had sufficient sequence coverage to be genotyped in 5818 individuals in average (99.9\% of the coding sequence). We considered as a rare missense variant, each missense variant observed at maximum 5 times among the cohort of individuals genotyped in EVS.

The occurrence of these rare variations were added together and divided by the mean of allele population to reach a theorical prevalence of rare variations in RYR2 in EVS, used as control population. The prevalence of rare $R Y R 2$ variations in our cohort (128 alleles or 64 patients) was then compared with the prevalence of $R Y R 2$ variations found in the population analysed in EVS (11636 alleles or 5818 individuals). We decided to pool both European and African ancestry for the comparison, first since our population of patients comprises both European and African ancestry and second because frequency of rare variants of $R Y R 2$ is similar in

European population and in African population. P value was calculated with Fisher's exact test. Calculations were carried out using the graphpad software: http://www.graphpad.com/quickcalcs/contingency1/.

RESULTS

\section{Clinical data}


1 All probands fulfilled TFC used at time of enrolment ${ }^{25}$ and four fulfilled recent update TFC ${ }^{2}$.

2 Clinical data are summarised in the tables 1 and S1. Pedigrees are presented in figure 1.

3 Family $A$.

4 The proband was a man presenting with aborted sudden cardiac death during intense effort,

5 with ventricular fibrillation. Resting ECG showed in V1 an atypical conduction defect (figure

6 2) and signal-averaged ECG detected late potentials. Cardiac imaging showed RV dilatation

7 and multifocal wall-motion-abnormalities (WMA) with mild left ventricle (LV) abnormalities

8 (table 1). He was found to carry a heterozygous RYR2 p.P1583S variant. The familial screening detected the variation in the affected father and a sister presenting with borderline phenotype while the three healthy relatives did not carry the variation. The father displayed frequent bimorphic ventricular ectopies and significant RV abnormalities on cardiac imaging. He also developed persistent atrial fibrillation needing cardioversion. The 17 year-old sister displayed a parietal block in V1 (figure 2) and mild RV abnormalities. Exercice test, EP study or isoproterenol test did not induced significant arrhythmia in the proband and his father.

\section{Family $B$.}

The proband was an asymptomatic 43-year-old man. He fulfilled diagnosis criteria for ARVC/D with the presence of T-wave inversion (TWI) from V1 to V4, non-sustained monomorphic ventricular tachycardia (NSVT) recording during the 24-hour 3D-ECG monitoring, frequent ventricular ectopies with left bundle branch block (LBBB) morphology and superior axis and late potentials (figure 2 and 3). He displayed a mild RV dilatation with global RV hypokinesia on cardiac-MRI. Electrophysiological mapping of the right ventricle showed a limited zone of scar within the inferior wall of the RV and the EP study triggered a monomorphic sustained ventricular tachycardia (SVT) with LBBB morphology and superior axis, suggesting ventricular tachycardia (VT) originating from this scar (figure 3). The molecular analysis of $R Y R 2$ found a p.L4670V heterozygous variation, also found in his 
1 affected sister and his asymptomatic mother (figure 2). His sister displayed TWI from V1 to

2 V3 without evidence of morphological abnormalities or ventricular arrhythmias (figure 2,

3 table 1 and Supplementary table 1) while their mother only displayed positive late-potentials.

\section{$4 \quad$ Family $C$}

5 This 59 years old male proband was a sporadic case that presented with presyncope and

6 spontaneous ventricular arrhythmia, corresponding to monomorphic NSVT with a LBBB morphology and inferior axis. ECG showed complete right bundle branch block (RBBB). Echocardiography and cardiac MRI showed apical and RVOT dyskinesia although the RV was not significantly enlarged. He did not reach the 2010 diagnosis criteria and was then considered with a borderline diagnosis of ARVC/D. The EP study and the isoproterenol test were negative under beta-blockers. The $R Y R 2$ p.G2367R heterozygous variation was identified. No DNA from relatives was available.

\section{Family $D$.}

The proband was a sporadic case that presented with palpitations and several episodes of syncope since the age of 35 . ECG showed TWI from V1 to V3 and late potentials (figure 2). He displayed spontaneous monomorphic sustained ventricular tachycardia of LBBB morphology. Cardiac imaging showed RV dilatation and dysfunction associated with apical and infero-basal WMA. Monomorphic NSVT with LBBB morphology and superior axis was triggered at EP study but not at exercise test and during isoproterenol test (figure 3). The p.A2213S heterozygous variation was identified in $R Y R 2$. One of the unaffected daughters, 12 years of age, carried the variation.

\section{Family $E$.}

Proband was a sporadic case that presented with presyncope at the age of 41 . Resting ECG showed TWI from V1 to V3 .The 24h-ECG monitoring detected frequent monomorphic ventricular ectopies (Vec) (figure2, table S1) decreasing during exercising. Cardiac imaging 
1 showed WMA with dyskinesia and RV aneurysm but no RV dilatation and therefore did not

2 reach the 2010 diagnostic criteria. The heterozygous p.V3219M variation in $R Y R 2$ was

3 identified.

$4 \quad$ Family $\boldsymbol{F}$.

5 Proband, a 39 years old woman, presented with palpitations and dyspnea. ECG showed 6 epsilon wave, first-degree atrio-ventricular block, incomplete RBBB. She developed atrial 7 fibrillation (figure 2). A 24h ECG monitoring and exercise test detected frequent polymorphic ventricular ectopies, increasing with effort (figure2, table S1). The EP study induced a syncopal polymorphic SVT. She developed a major RV dilatation with severe tricuspid regurgitation leading to end-stage heart failure that required heart transplantation. The anatomopathological study of the explanted heart confirmed typical histological features of ARVC/D with an extensive fibro-fatty replacement of the entire RV anterior wall associated with lymphocytes infiltration and important areas of fibro-fatty replacement within the LV wall (figure 4). A heterozygous p.Y2932H variation in $R Y R 2$ was identified. Familial screening detected the variation in two asymptomatic siblings.

None of the six probands presented with bidirectional VT. Mutation carriers did not show NSVT nor SVT during exercice test (performed in three probands and two relatives) or during isoproterenol test (performed in four probands and one relative).

\section{Genetic analysis}

We identified six unique rare missense variants in $R Y R 2$ among our panel of 64 desmosomenegative ARVC/D probands: p.P1583S, p.A2213S, p.G2367R, p.Y2932H, p.V3219M, p.L4670V (table 2). It corresponded to a yield of rare RYR2 variants of 9\% (6/64) in our cohort.

$R Y R 2$ is reported to be a relatively polymorphic gene by Jabbari et $\mathrm{al}^{26}$. We decided therefore to analyse whether the prevalence of $R Y R 2$ variant in our cohort was higher or not than in the 
general population. We estimated the prevalence of the genetic background noise of $R Y R 2$ variants in the general population using the data from the Exome Variant Server. We considered as a rare $R Y R 2$ variant a variant observed at maximum 5 times in EVS, which is a conservative approach. We observed that a rare $R Y R 2$ variant was identified in $215 / 5818$ subjects in EVS (supplementary table 2). It corresponded to a rate of rare $R Y R 2$ variants of $4 \%(215 / 5818)$ in EVS which was significantly lower to the $9 \%(6 / 64)$ observed in our cohort (Fisher test, $\mathrm{p}=0.0322$ ).

The variations p.A2213S, p.Y2932H and p.L4670V were novel.

The p.P1583S variation is located in the cytoplasmic part of the protein, outside the hot spot of mutations of $R Y R 2$. The proline residue at position 1583 is highly conserved among species and isoforms of $R Y R$ (figure 5). The variation was predicted to be deleterious by all prediction software (table 2), and was absent among 400 control chromosomes and from the EVS and 1000 genome databases.

The p.G2367R was located in the cytoplasmic part of the protein in the second hot spot domain of RYR2 (central domain), close to the region of interaction with FKBP12.6, a major regulatory protein of $R Y R 2$. Moreover, this variant has been previously reported in association with hypertrophic cardiomyopathy and unexplained sudden cardiac death and functional studies showed a gain of function ${ }^{27,28}$. This variation was not found in 400 control chromosomes.

The p.L4670V variation mapped to the transmembrane domain of the protein that participates to the pore of the calcium channel. This domain is a hot spot for $R Y R 2$ mutations, with more than 30 mutations published, all associated so far with CPVT or sudden death. Moreover, a p.L4670H variation has been recently reported in association with CPVT $^{26}$. The variation affected a highly conserved leucine residue (figure 5), was predicted as deleterious by all 
1 prediction softwares (table 2) and was found neither in 400 control chromosomes, nor in the

2 variant databases.

3 The p.A2213S, p.Y2932H, p.V3219M variations were located outside the hot spot of

4 mutations of $R Y R 2$, and modified a not conserved amino acid. They were absent from 400

5 control chromosomes but the p.V3219M variant was reported with a very low frequency

$6 \quad(<0.0001 \%)$ from Exome Variant Server database.

7

8

9

\section{DISCUSSION}

\section{Pathogenicity of RYR2 variants in ARVC/D}

We performed the first systematic screening of the whole $R Y R 2$ gene (105 exons and intronexon junctions) in a well clinically characterized ARVC/D cohort, after the exclusion of affected subjects harboring pathological mutations in either of the five desmosomal genes (PKP2, DSG2, DSP , JUP, DSC2). Among the 64 ARVC/D probands, we found a prevalence of rare $R Y R 2$ variants of $9 \%$. Based on a conservative approach including the estimation of a "genetic background noise" of $4 \%$ in $R Y R 2$, we found a significantly higher frequency of $R Y R 2$ variants in our ARVC/D cohort.

In the absence of functional studies, it remains difficult to classify any missense mutation as benign or pathogenic. Therefore, interpretation of our results was performed with considerable caution. We postulate that some of the new variants identified in our study are deleterious, either as a monogenic dominant mutation or through a modifier effect, while we cannot exclude the hypothesis that some variants may be very rare benign polymorphisms. The two variants, p.P1583S and p.L4670V were considered as highly probably pathogenic based on the conservation of the amino acid concerned, the absence of a large control population and the damaging effect predicted in silico. The familial studies showed that the 
1

variants segregate with the phenotype but with reduced penetrance. The pathogenic effect of p.A2213S, p.G2367R, p.Y2932H, p.V3219M was more difficult to ascertain. In silico analyses suggest that these variants are possible benign polymorphisms or modifying variants rather than direct disease-causing mutations.

Noticeably, we identified the presence of the two RYR2 SNPs (p.G1885E and p.G1886S) in a compound heterozygous manner in one additional proband, which were previously reported to be associated with ARVC/D (data not shown) ${ }^{24}$. However, we also identified this association in a healthy control subject supporting a possible modifier effect of these variants rather than a causal role.

The RYR2 mutations identified so far in ARVC/D were located in the cytoplasmic region of the channel ${ }^{11,22,23}$. Similarly, all the genetic variants we identified were also located in the cytoplasmic part of the protein, except the p.L4670V variant, which is located into the transmembrane domain, a hot spot of $R Y R 2$ mutations associated with CPVT phenotypes ${ }^{29}$. We therefore believe that the molecular analyse of $R Y R 2$ in ARVC/D requires the screening of the entire coding region of the gene.

\section{Phenotype/genotype analysis}

Until now, only few studies reported RYR2 mutations associated with ARVC/D $11,22,23$ (ARVC2 locus). In those families, the phenotype linked to $R Y R 2$ mutations appeared different from desmosome-related ARVC/D and presented overlapped characteristics with $\mathrm{CPVT}^{11}$. Interestingly, in the present study, the phenotype associated with $R Y R 2$ variants is similar to desmosome-related ARVC/D. Most probands fulfilled ARVC/D diagnosis based on recent update $\mathrm{TFC}^{25}$. They exhibited frequent TWI or parietal block on right precordial leads, which are common ARVC/D features absent from the CPVT and the ARVC2 phenotype. All probands displayed ventricular arrhythmias that were predominantly monomorphic with a LBBB morphology, which is a usual feature of ARVC/D, in opposite to the polymorphic 
arrhythmias encountered in CPVT or ARVC2. Ventricular effort-induced polymorphic ventricular arrhythmias are an important diagnosis feature of ARVC2 and CPVT ${ }^{19,21}$, however this feature was rarely present in our RYR2-related ARVC/D cohort (supplementary table 1). The p.P1583S carriers exhibited a phenotype closer to ARVC2 with effort-induced ventricular fibrillation and polymorphic VEc associated with significant RV abnormalities and few baseline ECG abnormalities. All patients displayed right ventricular cardiomyopathy with either RV dilatation and/or WMA usually encountered in ARVC/D. The endocardial mapping of the proband carrying the putative p.L4670V mutation showed a zone of scar tissue within the inferior RV wall. One proband developed a severe biventricular cardiomyopathy leading to heart transplant. The explanted heart showed typical histological features of ARVC/D with extensive fibro-fatty replacement of myocytes.

\section{Role of RYR2 variants in ARVC/D physiopathology}

The $\mathrm{Ca}^{2+}$ release channel $R Y R 2$ plays a central role in cardiac excitation-contraction coupling ${ }^{30}$. During the systole, $R Y R 2$ massively releases $\mathrm{Ca}^{2+}$ from the sarcoplasmic reticulum (SR) towards the cytoplasm leading to the cardiac contraction. Recently, a mutation affecting the phospholamban (PLN gene), another protein playing a central role in calcium regulation, has been described in an ARVC/D and DCM (dilated cardiomyopathy) population ${ }^{17}$.

Even if the PLN phenotype is possibly particular or overlapping, this observation might suggest a potential link between $\left[\mathrm{Ca}^{2+}\right]$ dysregulation and arrhythmogenic cardiomyopathies. It could be hypothesised that modifications of intracellular calcium homeostasis induced by $R Y R 2$ mutations might alter signaling pathways dependent of intracellular $\mathrm{Ca}^{2+}$ homeostasis, and participate to the pathogenesis of $\mathrm{ARVC} / \mathrm{D}$. However, this hypothesis requires further investigations.

\section{Limits}


1 A limit of this study is the absence of definitive demonstration for the pathogenicity of the

$2 \quad R Y R 2$ variants, because of inconclusive segregation analyses and no available functional

3 studies. However, one of the variants was previously reported to cause a gain of function ${ }^{27,28}$.

4 Moreover, the small size of families is quite usual in ARVC/D because of reduced penetrance 5 and therefore few affected relatives in a family. In addition we performed a careful and 6 conservative interpretation of the variants.

7 Another limit concerns the comparison of the rate of $R Y R 2$ variants in our cohort and in EVS cohort while two different methods of sequencing were used, which performance may differ (error rate, coverage). However, their efficiency in term of error rate seems to be similar ${ }^{31}$ and the coverage of the coding sequence of RYR2 in EVS was excellent (99.9\%). We are therefore confident with the true difference of $R Y R 2$ variants in patients and controls, although the analysis of a larger cohort of patients with NGS could strengthen our findings.

At last, the ARVC/D probands were selected according to the 1994 Task Force Criteria as this cohort was prospectively recruited before the publication of the revised TFC.

\section{CONCLUSION}

We performed the first systematic screening of the whole $R Y R 2$ gene in a well clinically characterized ARVC/D cohort, after the exclusion of patients with pathological mutations in five desmosomal genes, and identified putative RYR2 mutations in 9\% of ARVC/D probands. Furthermore, we observed that $R Y R 2$ variants were associated with ARVC/D not overlapping with CPVT phenotype. This observation suggests that $R Y R 2$ variants play a role in the genetic basis of conventional ARVC/D either as disease-causing mutation, or a modifier gene. This study also support the notion that in case of a missense variant identified in $R Y R 2$ in ARVC/D patient, it is necessary to be particularly cautious in the interpretation of the pathogenicity of the variant. The screening of multiple genes, including $R Y R 2$, in ARVC/D populations in 
1 association with careful phenotype/genotype correlations and functional studies will help to

2 better understand the complex genetic background of this disease.

3

\section{ACKOWLEDGMENTS}

5 The study would not have been possible without the invaluable assistance of the patients. This

6 work was supported by grants from Assistance Publique-Hôpitaux de Paris [PHRC

7 programme hospitalier de recherche clinique AOM05073]. We thank $\mathrm{Dr}$ P. Ray for 8 proofreading the manuscript and Dr J. Brocard for statistical analyses.

9

10

11 


\section{REFERENCES}

1 Basso C, Corrado D, Marcus FI, Nava A, Thiene G. Arrhythmogenic right ventricular cardiomyopathy. Lancet 2009; 373: 1289-1300.

2 Marcus FI, McKenna WJ, Sherrill D, et al. Diagnosis of arrhythmogenic right ventricular cardiomyopathy/dysplasia: proposed modification of the Task Force Criteria. Eur Heart J 2010; 31: 806-814.

3 Gerull B, Heuser A, Wichter $\mathrm{T}$, et al. Mutations in the desmosomal protein plakophilin-2 are common in arrhythmogenic right ventricular cardiomyopathy. Nat Genet 2004; 36: 1162-1164.

4 Pilichou K, Nava A, Basso C, et al. Mutations in desmoglein-2 gene are associated with arrhythmogenic right ventricular cardiomyopathy. Circulation 2006; 113: 11711179.

5 Awad MM, Dalal D, Cho E, et al. DSG2 mutations contribute to arrhythmogenic right ventricular dysplasia/cardiomyopathy. Am J Hum Genet 2006; 79: 136-142.

6 McKoy G, Protonotarios N, Crosby A, Tastsopoulou A, Anastasakis A, Coonar A, Norman M, Baboonian C, Jeffery S, McKenna WJ. Identification of a deletion in plakoglobin in arrhythmogenic right ventricular cardiomyopathy with palmoplantar keratoderma and woolly hair (Naxos disease). Lancet 2000; 355: 2119-2124.

7 Norgett EE, Hatsell SJ, Carvajal-Huerta L, et al. Recessive mutation in desmoplakin disrupts desmoplakin-intermediate filament interactions and causes dilated cardiomyopathy, woolly hair and keratoderma. Hum Mol Genet 2000; 9: 2761-2766.

8 Syrris P, Ward D, Evans A, Asimaki A, Gandjbakhch E, Sen-Chowdhry S, McKenna WJ. Arrhythmogenic right ventricular dysplasia/cardiomyopathy associated with mutations in the desmosomal gene desmocollin-2. Am J Hum Genet 2006; 79: 978984. 
19 Heuser A, Plovie ER, Ellinor PT, et al. Mutant desmocollin-2 causes arrhythmogenic right ventricular cardiomyopathy. Am J Hum Genet 2006; 79: 1081-1088.

Fressart V, Duthoit G, Donal E, et al. Desmosomal gene analysis in arrhythmogenic right ventricular dysplasia/cardiomyopathy: spectrum of mutations and clinical impact in practice. Europace 2010; 12: 861-868.

11 Tiso N, Stephan DA, Nava A, et al. Identification of mutations in the cardiac ryanodine receptor gene in families affected with arrhythmogenic right ventricular cardiomyopathy type 2 (ARVD2). Hum Mol Genet 2001; 10: 189-194.

12 Beffagna G, Occhi G, Nava A, et al. Regulatory mutations in transforming growth factor-beta3 gene cause arrhythmogenic right ventricular cardiomyopathy type 1 . Cardiovasc Res 2005; 65: 366-373.

13 Merner ND, Hodgkinson KA, Haywood AF, et al. Arrhythmogenic right ventricular cardiomyopathy type 5 is a fully penetrant, lethal arrhythmic disorder caused by a missense mutation in the TMEM43 gene. Am J Hum Genet 2008; 82: 809-821.

14 Quarta G, Syrris P, Ashworth M, Jenkins S, Zuborne Alapi K, Morgan J, Muir A, Pantazis A, McKenna WJ, Eliott PM. Mutations in the Lamin A/C gene mimic arrhythmogenic right ventricular cardiomyopathy. Eur Heart J 2012; 33: 1128-1136.

15 Taylor M, Graw S, Sinagra G, et al. Genetic variation in titin in arrhythmogenic right ventricular cardiomyopathy-overlap syndromes. Circulation 2011; 124: 876-885.

16 Otten E, Asimaki A, Maass A, van Langen I, van der Wal A, de Jonge N, van der Berg MP, Saffitz JE, Wilde AA, Jongbloed JD, van Tintelen JP. Desmin mutations as a cause of right ventricular heart failure affect the intercalated disks. Heart Rhythm 2010; 7: 1058-1064.

17 van der Zwaag PA, van Rijsingen IA, Asimaki A, et al. Phospholamban R14del mutation in patients diagnosed with dilated cardiomyopathy or arrhythmogenic right 
ventricular cardiomyopathy: evidence supporting the concept of arrhythmogenic cardiomyopathy. Eur J Heart Fail 2012; 14: 1199-1207.

Laitinen PJ, Brown KM, Piippo K, et al. Mutations of the cardiac ryanodine receptor (RyR2) gene in familial polymorphic ventricular tachycardia. Circulation 2001; 103 : 485-490.

19 Priori SG, Napolitano C, Tiso N, Memmi M, Vignati G, Bloise R, Sorrentino V, Danieli GA. Mutations in the cardiac ryanodine receptor gene (hRyR2) underlie catecholaminergic polymorphic ventricular tachycardia. Circulation 2001; 103: 196200.

20 Nava A, Canciani B, Daliento L, Miraglia G, Buja G, Fasoli G, Martini B, Scognamiglio R, Thiene G. Juvenile sudden death and effort ventricular tachycardias in a family with right ventricular cardiomyopathy. Int J Cardiol 1988; 21: 111-126.

21 Rampazzo A, Nava A, Erne P, Eberhard M, Vian E, Slomp P, Tiso N, Thiene G, Danieli GA. A new locus for arrhythmogenic right ventricular cardiomyopathy (ARVD2) maps to chromosome 1q42-q43. Hum Mol Genet 1995; 4: 2151-2154.

22 Bauce B, Rampazzo A, Basso C, Bagattin A, Daliento L, Tiso N, Turrini P, Thiene G, Danieli GA, Nava A. Screening for ryanodine receptor type 2 mutations in families with effort-induced polymorphic ventricular arrhythmias and sudden death: early diagnosis of asymptomatic carriers. J Am Coll Cardiol 2002; 40: 341-349.

23 d'Amati G, Bagattin A, Bauce B, et al. Juvenile sudden death in a family with polymorphic ventricular arrhythmias caused by a novel RyR2 gene mutation: evidence of specific morphological substrates. Hum Pathol 2005; 36: 761-767.

24 Milting H, Lukas N, Klauke B, Korfer R, Perrot A, Osterziel KJ, Vogt J, Peter S, Thieleczek R, Varsanyi M. Composite polymorphisms in the ryanodine receptor 2 
gene associated with arrhythmogenic right ventricular cardiomyopathy. Cardiovasc Res 2006; 71: 496-505.

25 McKenna WJ, Thiene G, Nava A, Fontaliran F, Blomstrom-Lundqvist C, Fontaine G, Camerini F. Diagnosis of arrhythmogenic right ventricular dysplasia/cardiomyopathy. Task Force of the Working Group Myocardial and Pericardial Disease of the European Society of Cardiology and of the Scientific Council on Cardiomyopathies of the International Society and Federation of Cardiology. Br Heart J 1994; 71: 215-218.

26 Jabbari J, Jabbari R, Nielsen MW, Holst AG, Nielsen JB, Haunso S, Tfelt-Hansen J, Svendsen JH, Olesen MS. New exome data question the pathogenicity of genetic variants previously associated with catecholaminergic polymorphic ventricular tachycardia. Circ Cardiovasc Genet 2013; 6: 481-489.

27 Larsen MK, Berge KE, Leren TP, Nissen PH, Hansen J, Kristensen IB, Banner J, Jensen HK. Postmortem genetic testing of the ryanodine receptor 2 (RYR2) gene in a cohort of sudden unexplained death cases. Int J Legal Med 2013; 127: 139-144.

28 Thomas NL, George CH, Williams AJ, Lai FA. Ryanodine receptor mutations in arrhythmias: advances in understanding the mechanisms of channel dysfunction. Biochem Soc Trans 2007; 35: 946-951.

29 Priori SG, Chen SR. Inherited dysfunction of sarcoplasmic reticulum Ca2+ handling and arrhythmogenesis. Circ Res 2011; 108: 871-883.

30 Bers DM. Cardiac excitation-contraction coupling. Nature 2002; 415: 198-205.

31 Glenn TC. Field guide to next-generation DNA sequencers. Mol Ecol Resour 2011; 11: 759-769.

32 Du GG, Sandhu B, Khanna VK, Guo XH, MacLennan DH. Topology of the Ca2+ release channel of skeletal muscle sarcoplasmic reticulum (RyR1). Proc Natl Acad Sci U S A 2002; 99: 16725-16730. 
133 Wehrens $\mathrm{XH}$, Marks AR. Altered function and regulation of cardiac ryanodine receptors in cardiac disease. Trends Biochem Sci 2003; 28: 671-678.

3 


\section{CLINICAL PERSPECTIVES}

2 To our knowledge, we report here the first systematic screening of the whole $R Y R 2$ gene in a

3 large ARVC/D cohort without mutation in desmosomal genes. We identified six rare RYR2

4 missense variants predominantly associated with a conventional phenotype of ARVC/D.

5 Using the data from the Exome Variant Server database, we estimated the prevalence of rare

$6 \quad R Y R 2$ variants to $4 \%$ in the general population, which was significantly lower to the $9 \%$

7 observed in our cohort (Fisher test, $\mathrm{p}=0.0322$ ). The results support the role of $R Y R 2$ gene in

8 conventional ARVC/D. This study also highlights the fact that in case of a missense variant

9 identified in RYR2 in ARVC/D patient, it is necessary to be particularly cautious in the

10 interpretation of the pathogenicity of the variant given the prevalence of rare $R Y R 2$ variants in

11 the general population. The screening of multiple genes, including $R Y R 2$, in ARVC/D

12 populations in association with careful phenotype/genotype correlations and functional

13 studies will help to better understand the complex genetic background of this disease and to

14 improve the management of ARVC/D patients in the future. 
2 Figure 1. Family pedigrees of the patients with a $R Y R 2$ variant.

3 Square: male, circle: women, white: unaffected individuals after clinical examination or with

4 no known disease, black: affected, grey: borderline (TFC 2010). +/-: heterozygous

5 individuals, -/-: individuals negative. NA: genetic status not available. aSCD: aborted sudden

6 cardiac death

7

\section{Figure 2. Electrocardiographic characteristics of $R Y R 2$ variants carriers}

Proband II:1, family A displayed an unusual intraventricular conduction defect in lead V1

\section{Figure 3. Electrophysiological data.}

Proband II:1, family B developed spontaneous monomorphic NSVT recorded during the 24hours ECG monitoring. The electrophysiological study triggered a SVT with LBBB morphology and superior axis (left), close to the spontaneous ventricular ectopies morphology (right). EP study performed on proband II:4, family D triggered NSVT with LBBB morphology.

\section{Figure 4. Histological data.}

Histological characterisation of the proband from family F. The figure showed typical fibrofatty replacement in the right ventricle anterior wall of explanted heart (haematoxylin and eosin staining, x20 and x100 magnification) 
1 Figure 5. Location and conservation of the $R Y R 2$ variants identified.

2 (A) Location: all missense variants are located within the intra-cytoplasmic part or the 3 protein, at the exception of the p.L4670V, which is located within the trans-membranous part 4 of the protein $^{32,33}$. (B) The conservation of the mutated residues 1583 and 4670 indicate that 5 they are highly conserved across human isoforms and species.

6

7

8 
Table 1. Clinical characteristics of probands $R Y R 2$ mutation carriers.

\begin{tabular}{|c|c|c|c|c|c|c|c|c|c|c|c|c|c|c|c|c|}
\hline 育 & 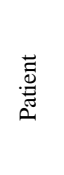 & 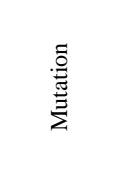 & $\stackrel{\substack{\infty \\
\ll}}{2}$ & 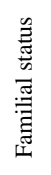 & 蔫 & 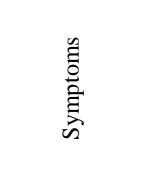 & 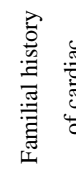 & 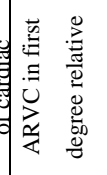 & 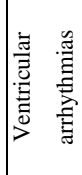 & 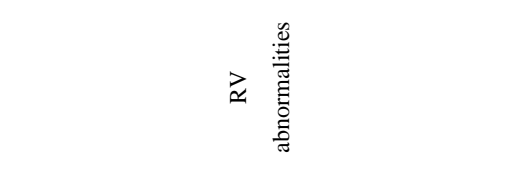 & 〉莺 & ني & $\begin{array}{l}0 \\
\text { UI } \\
\mathbb{4} \\
\text { in }\end{array}$ & $\begin{array}{l}\overrightarrow{00} \\
\overrightarrow{0} \\
\overrightarrow{0} \\
\text { 量 }\end{array}$ & 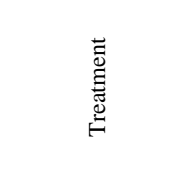 & 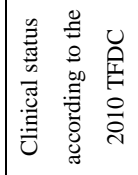 \\
\hline \multirow{3}{*}{ A } & II: 1 & p.P1583S & 22 & $\mathrm{~Pb}$ & Europe & Aborted SCD & none & no & Yes* & $\begin{array}{l}\text { Dilated RV, apical trabeculations, infero-lateral } \\
\text { dyskinesia and akinesia of antero lateral RVOT } \\
\text { (echo, MRI, angiography)** }\end{array}$ & $\begin{array}{c}\text { Mild LV dilatation } \\
\text { and infero-basal } \\
\text { hypokinesia }\end{array}$ & $\begin{array}{c}\text { Intravaentricular } \\
\text { conduction defect in } \\
\text { V1 }\end{array}$ & $3 / 3 *$ & $\mathrm{NA}$ & BB, ACEi, ICD & Affected \\
\hline & II:3 & p.P1583S & 17 & $\mathrm{R}$ & Europe & none & Yes & Yes** & none & $\begin{array}{c}\text { Mild RV dilatation on echocardiography with } \\
\text { lowered RV FAC } 27 \% \text { and dyssynchronous RV } \\
\text { contraction with apico-lateral hypokinesia on } \\
\text { cardiac-MRI (echo/MRI) }\end{array}$ & none & $\begin{array}{c}\text { Terminal QRS } \\
\text { duration }>55 \mathrm{~ms} \text { in } \\
\mathrm{V} 1 *\end{array}$ & $0 / 3$ & NA & none & Borderline \\
\hline & $\mathrm{I}: 1$ & p.P1583S & 60 & $\mathrm{R}$ & Europe & none & none & Yes** & Yes* & $\begin{array}{l}\text { RV apical akinesia associated with RV enlargement } \\
\text { (RVOT measured at } 34 \mathrm{~mm} \text { PSAX view) (echo, } \\
\text { angiography)* }\end{array}$ & $\mathrm{LVEF}=55 \%$ & $\begin{array}{l}\mathrm{AF}, \text { Terminal QRS } \\
\text { duration }>55 \mathrm{~ms} \text { in } \\
\mathrm{V} 1 *\end{array}$ & $0 / 3$ & NA & BB & Affected \\
\hline \multirow{2}{*}{ B } & II:1 & p.L4670V & 43 & $\mathrm{~Pb}$ & Europe & none & none & no & Yes* & $\begin{array}{c}\text { Mild RV dilatation (RV end-diastolic volume = } 109 \\
\mathrm{ml} / \mathrm{m}^{2} \text { ) and global hypokinesia } \\
\mathrm{RV} \text { EF 36\% (echo,MRI) }\end{array}$ & none & TWI V1-4** & $1 / 3 *$ & NA & BB & Affected \\
\hline & $\mathrm{I}: 2$ & p.L4670V & 70 & $\mathrm{R}$ & Europe & none & Yes & Yes** & none & None (echo, MRI, scintigraphy) & none & Normal & $2 / 3 *$ & NA & none & borderline \\
\hline $\mathrm{C}$ & II:3 & p.G2367R & 59 & $\mathrm{~Pb}$ & $\begin{array}{l}\text { North } \\
\text { africa }\end{array}$ & Presyncope & none & no & Yes* & $\begin{array}{l}\text { WMA with apical and RVOT akinesia, RV LGE* } \\
\text { (echo, MRI, scintigraphy) }\end{array}$ & none & $\begin{array}{c}\text { RBBB; } \\
\text { QRS V1/6>25ms }\end{array}$ & $\begin{array}{c}3 / 3 \\
\text { QRS }>110 \mathrm{~ms}\end{array}$ & $\mathrm{NA}$ & $\begin{array}{l}\text { BB, amiodarone, } \\
\text { ACEi, ICD }\end{array}$ & Borderline \\
\hline \multirow[t]{2}{*}{ D } & II: 4 & p.A2213S & 35 & $\mathrm{~Pb}$ & Europe & $\begin{array}{l}\text { Palpitations } \\
\text { syncope }\end{array}$ & none & no & Yes* & $\begin{array}{c}\text { RV dilatation (RVOT at } 50 \mathrm{~mm} \text { in PSAX view) } \\
\text { RV dysfunction (RV FAC : } 26 \% \text { ), apical akinesia } \\
\text { and infero-basal hypokinesia, } \mathrm{RV} \mathrm{LGE}^{* *} \text { (echo, } \\
\text { MRI) }\end{array}$ & $\mathrm{LVEF}=55 \%$ & TWI V1-3** & $1 / 3^{*}$ & NA & $\mathrm{BB}, \mathrm{ICD}$ & Affected \\
\hline & III: 1 & p.A2213S & 12 & $\mathrm{R}$ & Europe & none & Yes & Yes** & none & None (echo) & none & $\mathrm{Nl}$ & $0 / 3$ & NA & none & Unaffected \\
\hline E & II: 2 & p.V3219M & 41 & $\mathrm{~Pb}$ & Europe & Presyncope & none & no & Yes* & $\begin{array}{l}\text { WMA with dyskinesia and RV aneurysm (echo, } \\
\text { MRI) }\end{array}$ & none & TWI V1-3** & $0 / 3$ & NA & BB & borderline \\
\hline \multirow{2}{*}{$\mathrm{F}$} & II: 4 & p.Y2932H & 39 & $\mathrm{~Pb}$ & Europe & $\begin{array}{l}\text { Palpitations } \\
\text { dyspnea }\end{array}$ & none & no & Yes* & $\begin{array}{l}\text { Major RV dilatation, antero akinesia, anterior } \\
\text { akinesia and infero-apical severe hypokinesia, } \\
\text { trabeculations (echo, angiography)** }\end{array}$ & $\begin{array}{c}\mathrm{LVEF}=45 \% \\
\text { Mild LV dilatation }\end{array}$ & $\begin{array}{c}\text { Epsilon wave, } \\
\text { incomplete } \mathrm{RBBB}, \\
\mathrm{AF}^{* *}\end{array}$ & $0 / 3$ & $\dagger * *$ & $\begin{array}{c}\text { Amiodarone, BB, } \\
\text { ACEi, ICD, Heart } \\
\text { Tx }\end{array}$ & Affected \\
\hline & II:3 & p.Y2932H & 41 & $\mathrm{R}$ & Europe & none & Yes & Yes** & none & None (echo) & none & $\mathrm{Nl}$ & $0 / 3$ & $\mathrm{NA}$ & none & Unaffected \\
\hline
\end{tabular}

ACEi: angiotensin conversion enzyme inhibitor; AF: atrial fibrillation; BB: beta-blockers; Echo: echocardiography; EF: ejection fraction; FAC: fractional area change; Heart Tx: heart transplantation; ICD: implantable cardiac defibrillator; LGE: presence of late-gadolinium enhancement; LV: left ventricle; NA: non-available data; Pb: proband (all fulfilled 1994 diagnostic criteria available at enrolment); PSAX: para-sternal short axis; R: relative; RV: right ventricle; RBBB: right bundle branch block; SCD: sudden cardiac death; SAECG: signal average ECG; RVOT: right ventricle outflow tract; TWI: T-wave inversion; WMA: wall motion abnormalities; *: min or criteria according to the 2010 Task Force Diagnosis Criteria (TFDC); **: major criteria; $\uparrow$ : fibrofatty replacement. 
Table 2: Predicted alterations of nonsynonymous changes observed.

\begin{tabular}{|c|c|c|c|c|c|c|c|}
\hline \multirow{2}{*}{ Exon } & \multirow{2}{*}{ Mutation } & \multirow{2}{*}{ Location } & \multirow{2}{*}{ Conservation } & \multicolumn{3}{|c|}{ Prediction from bioinformatic tools } & \multirow{2}{*}{ Frequency in variant database* } \\
\hline & & & & SIFT & Polyphen2 & SNPsandGO & \\
\hline 36 & $\begin{array}{c}\text { c. } 4747 \mathrm{C}>\mathrm{T} \\
\text { p.P1583S }\end{array}$ & Cytoplasmic & yes & Intolerant & Probably damaging & Disease & $\begin{array}{l}\text { Not reported in EVS \& } 1000 \text { genomes } \\
\text { (but reported in NCBI (frequency 1/24 000)) }\end{array}$ \\
\hline 43 & $\begin{array}{l}\text { c. } 6637 \mathrm{G}>\mathrm{T} \\
\text { p.A2213S }\end{array}$ & Cytoplasmic & no & Intolerant & Possibly damaging & Disease & Not reported \\
\hline 46 & $\begin{array}{l}\text { c.7099G>A } \\
\text { p.G2367R }\end{array}$ & Cytoplasmic & no & Tolerant & Possibly damaging & Neutral & $0.008 \%$ \\
\hline 60 & $\begin{array}{l}\text { c.8794T }>C \\
\text { p.Y2932H }\end{array}$ & Cytoplasmic & no & Tolerant & Probably damaging & Neutral & Not reported \\
\hline 68 & $\begin{array}{l}\text { c. } 9655 \mathrm{G}>\mathrm{A} \\
\text { p.V3219M }\end{array}$ & Cytoplasmic & no & Tolerant & Possibly damaging & Disease & $0.008 \%$ \\
\hline 97 & $\begin{array}{l}\text { c. } 14008 \mathrm{C}>\mathrm{G} \\
\text { p.L4670V }\end{array}$ & Transmembrane domain & yes & Intolerant & Probably damaging & Disease & Not reported \\
\hline
\end{tabular}

*Including NCBI, EVS (exome variant server) and 1000 genomes databases 
Family A. c.4747C $>$ T; p.P1583S

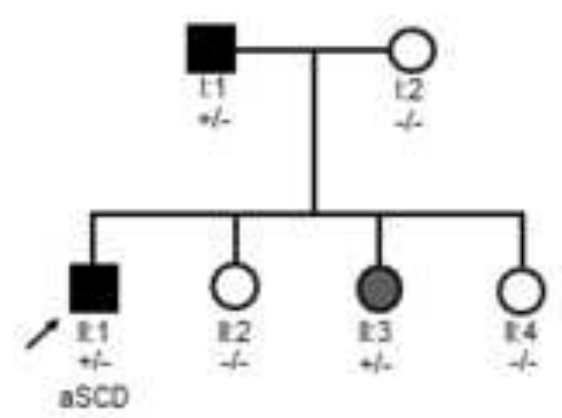

Family D. c.6637G $>T$; p.A2213S

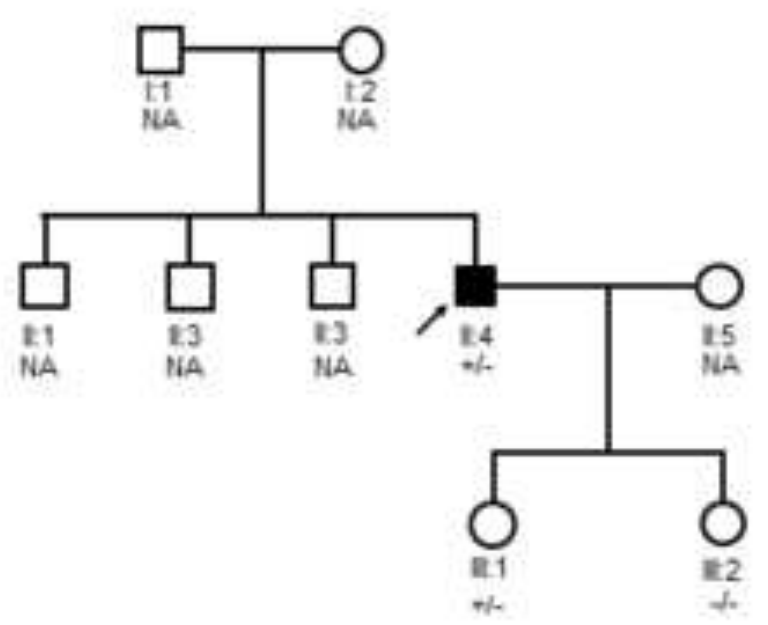

Family B. c.14008G $>$ A; p.L4670V

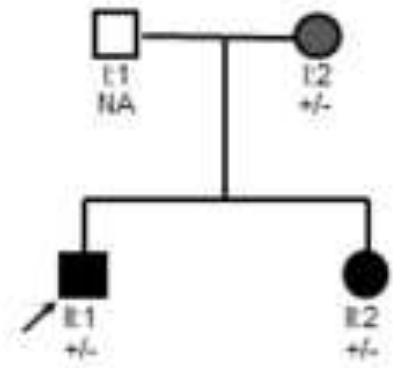

Family E. c.8794T $>$ C; p.V3219M

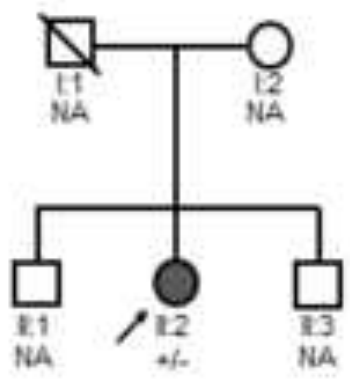

Family C. c.7099G $>A ;$ p.G2367R

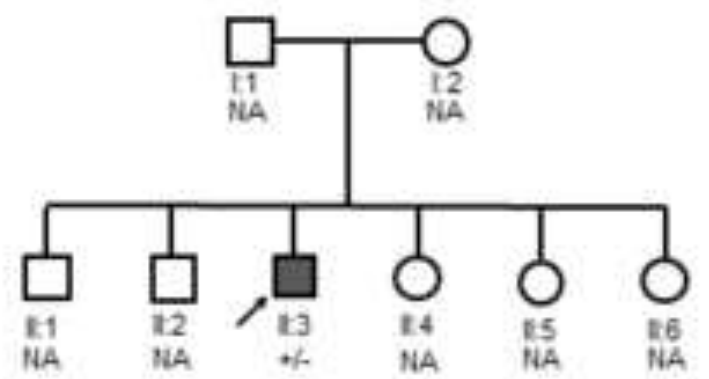

Family F. c.8794T $>$ C; p.Y2932H

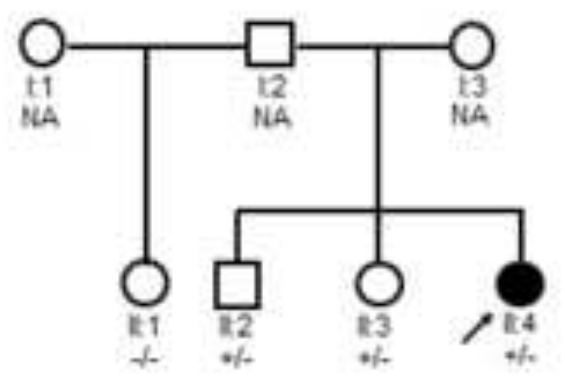


Click here to download high resolution image

\section{Electrocardiographic recording}

$>$ Fam A

Probasd (patient II:1) Relative (patient II:3)

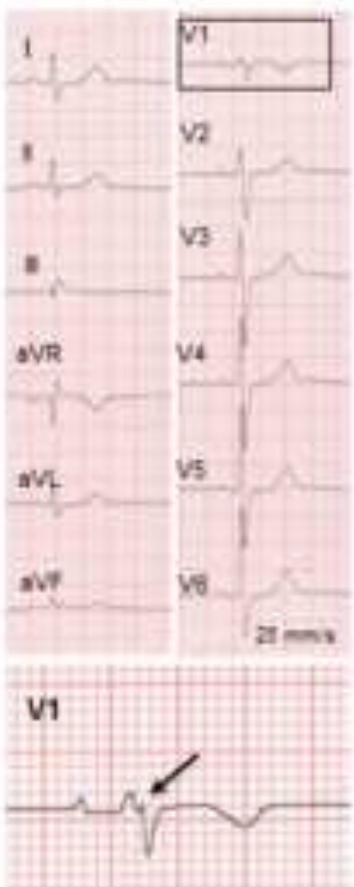

- Eam D

Proband (patient II:4)

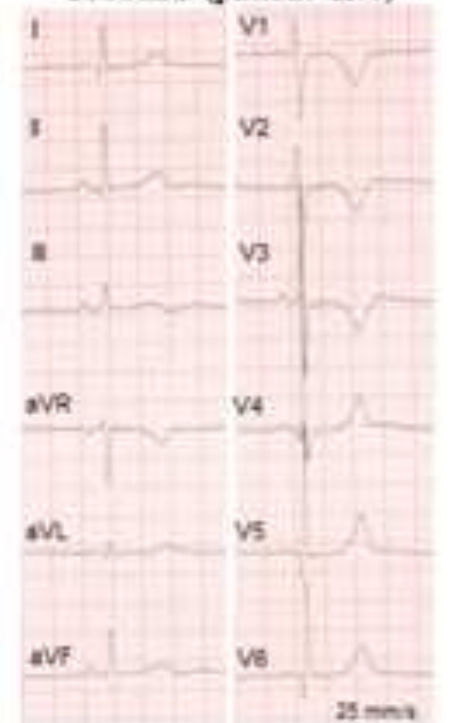

$>\operatorname{Fan} A$

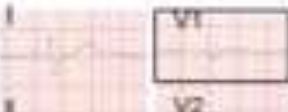

1

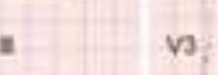

n 1

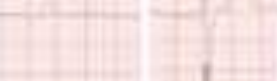

ava $\quad$ V4

and $x$

w va
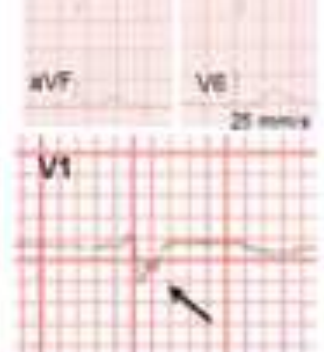

$>$ Fam E

Proband (patient II:2)

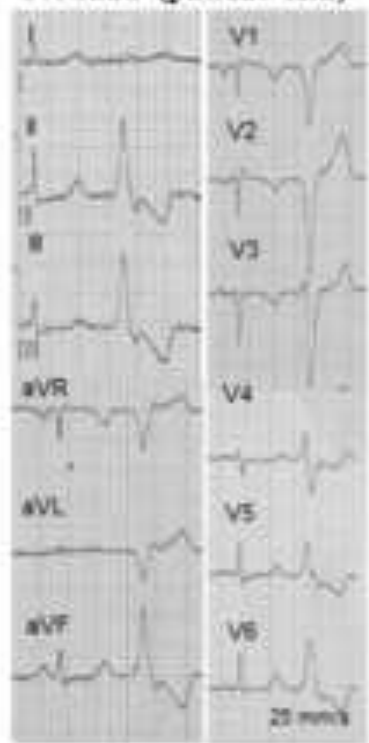

$>$ Fam B

Proband (patient II:1)

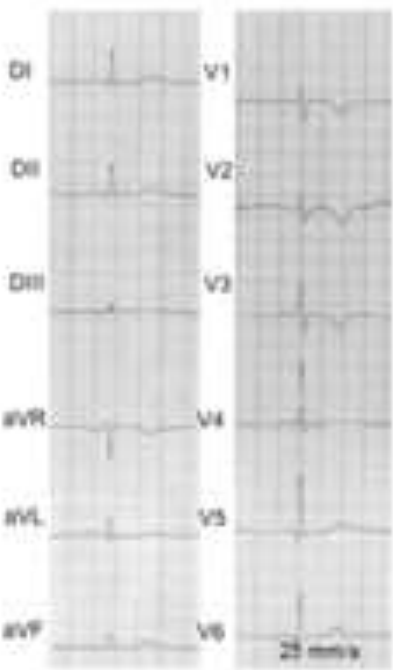

-Fam B

Relative (patieat II:2)

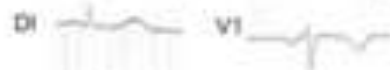

ou氺

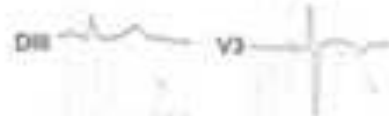

$\operatorname{mk} x+1-2$

$m-2 \quad v s-1$

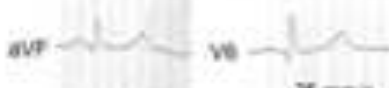

$>$ Fam F

Probasd (patient II:4)
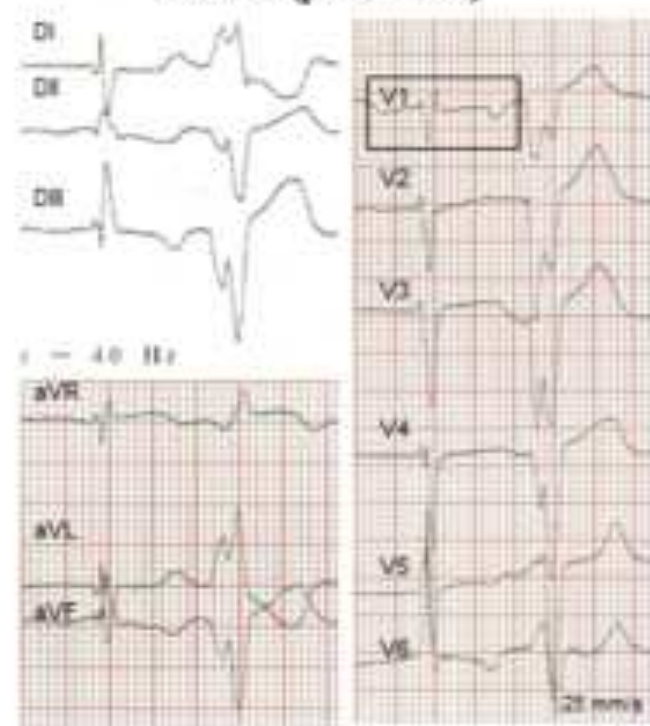

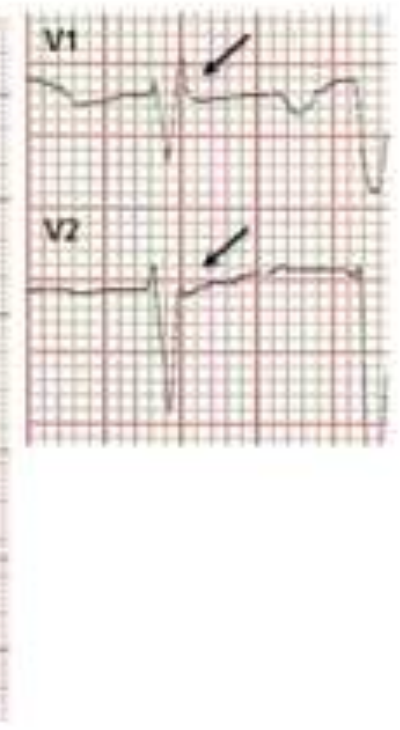


$>$ Proband (patient II:1), family B

Electrophysiological study

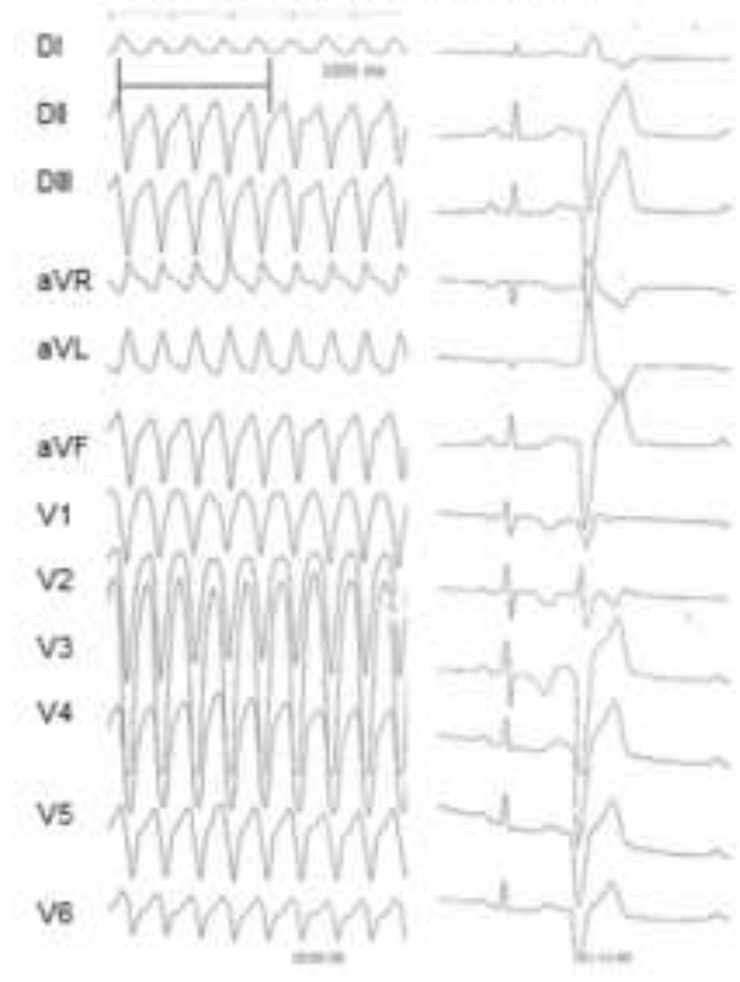

24-hours ECG monitoring

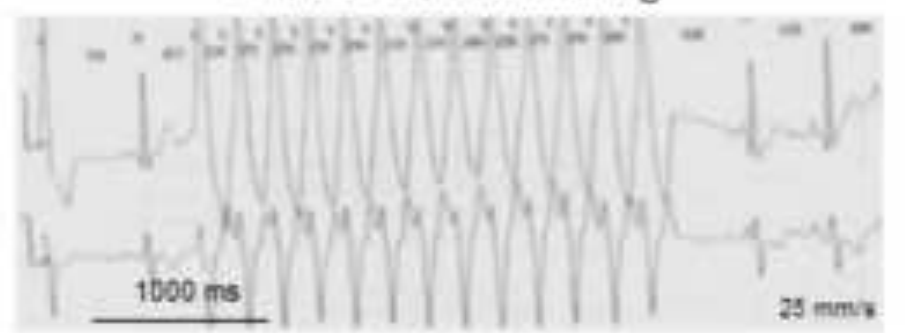

$>$ Proband (patient II:4), family D

Electrophysiological study.

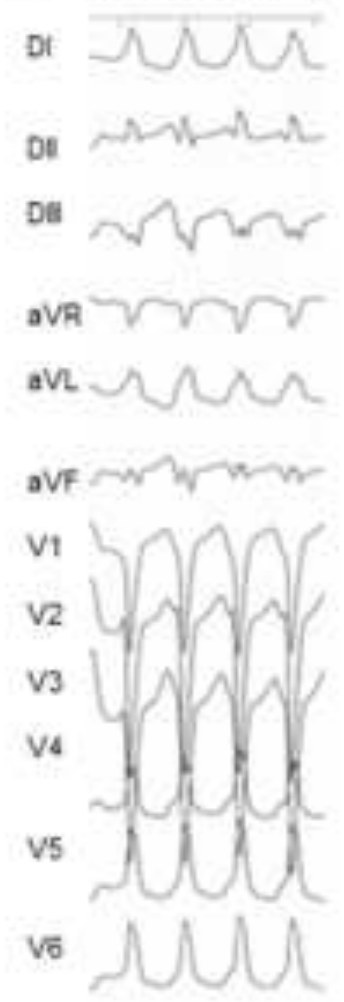

of $\rightarrow x+1$

Del

ava $\sqrt{\mathrm{r}} \sqrt{\mathrm{r}}$

avf rartworm 
Click here to download high resolution image

Histological characterisation of the proband (patient II:4), fam F.

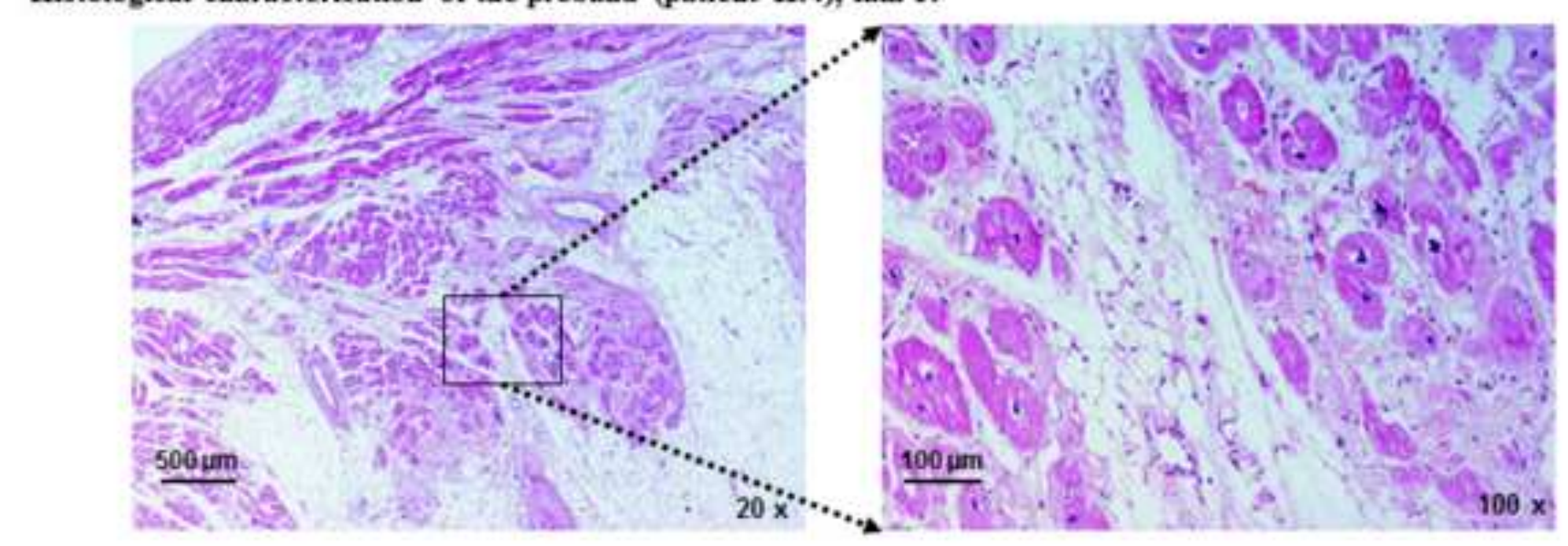


Figure 5
Click here to download high resolution image

A.

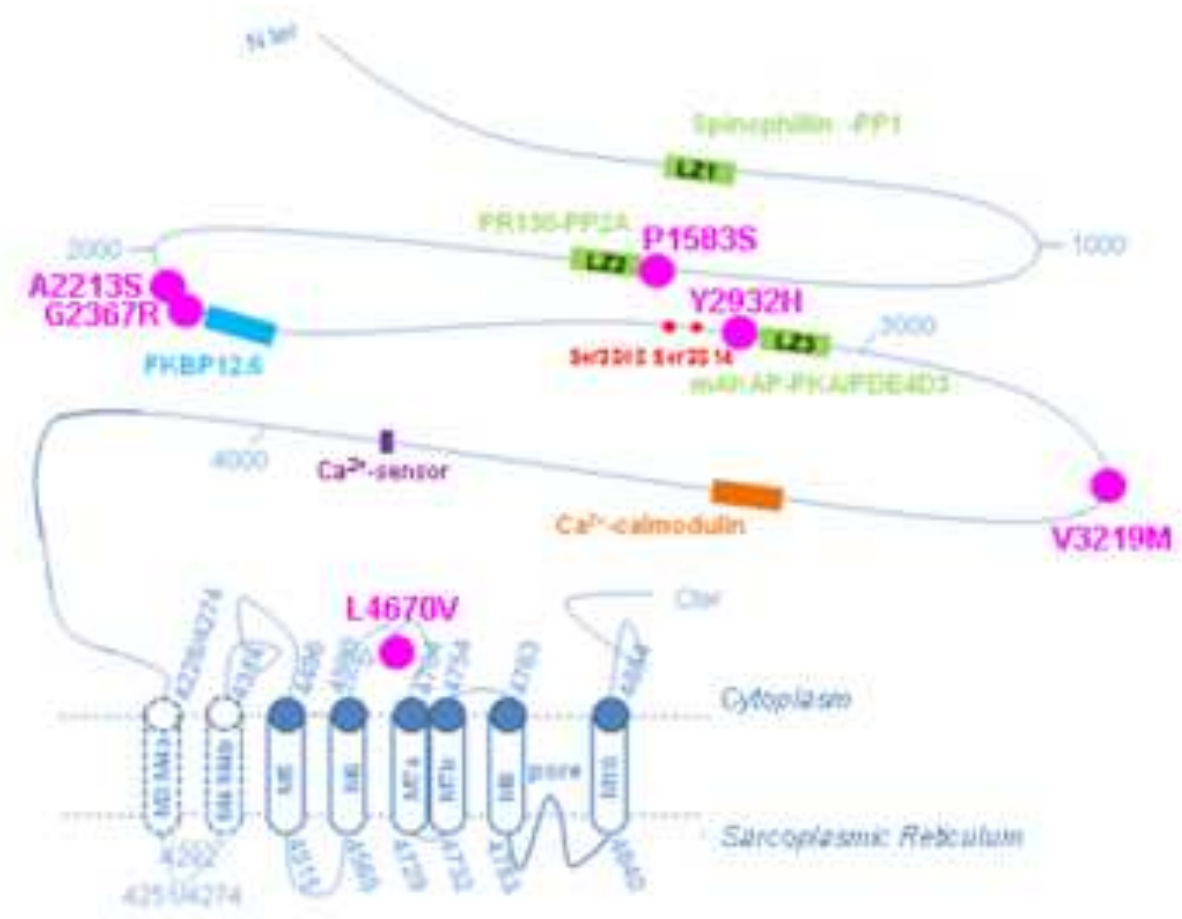

B.
RyR2 Huan

RyPL1 Huwan

RyR3 Human

RyR2 Rabbit

RyR1 P1g

RyR3 Chicken

Ryr Drosophila

RyRI C.elegans
4670

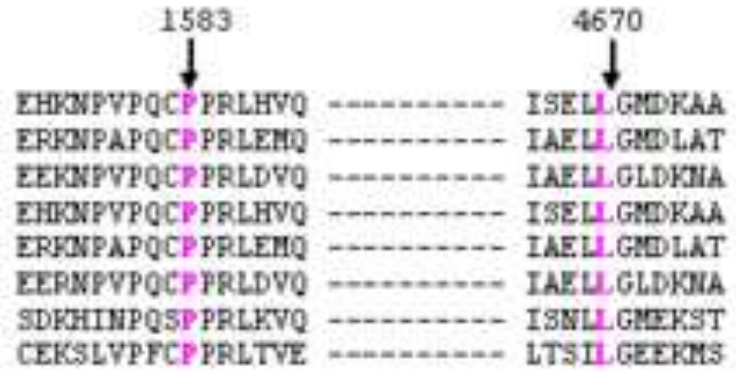




\section{Click here to download Supplementary Material: supplementary_table1.doc}

Supplementary Material
Click here to download S

.

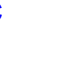

(n)

(a)

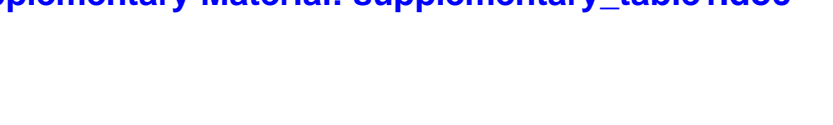

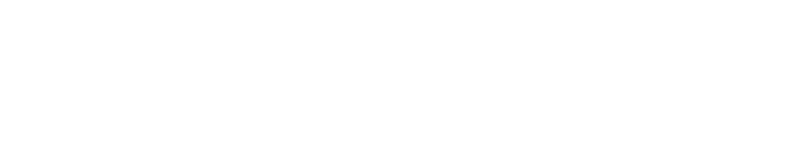
(1) (1) (1) (1) (1) (1) (1) (1) (1)

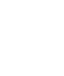

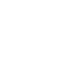

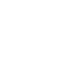

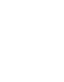
(1) 
Supplementary Material2
Click here to download Supplementary Material: supplementary_table2.doc

Supplementary Material2
Click here to download Supplementary Material: supplementary_table2.doc

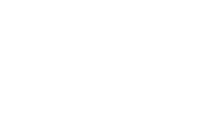

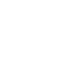

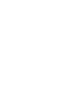

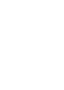

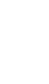

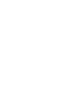

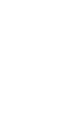

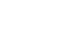
更

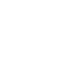

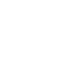
更

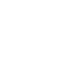

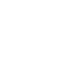

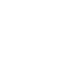
更

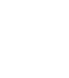

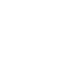

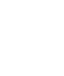

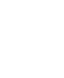

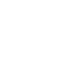

